680 DEVELOPMENT AND EVALUATION OF RETURN CALLS A TOOL TO ENHANCE RETURN TO WORK FOR LONGTERM ABSENTEEISM

${ }^{1} \mathrm{E}$ Carlier, 'S Roman*, ${ }^{1} \mathrm{~N}$ Doyen, ${ }^{1} \mathrm{~J}$ Vandevelde, ${ }^{1} \mathrm{M}-\mathrm{N}$ Schmickler, ${ }^{1,2} \mathrm{M}$ Verbrugghe. ${ }^{1}$ Mensura Occupational Health Services, Belgium; ${ }^{2}$ Department of Public Health, University of Ghent, Belgium

\subsection{6/oemed-2018-ICOHabstracts.482}

Introduction Since 2002, long-term absenteeism in Belgium has steadily increased each year. In 2016, 5.13\% of the Belgian working population was on sickness absence for $>1$ month. In Belgium, sickness-absence benefits are paid by the employer in the first month and subsequently by social security. To increase the RTW chances among employees with long-term absenteeism, Mensura Occupational Health Services (OHS) developed return calls.

Methods Mensura OHS developed the following procedure:

- Companies with long-term absentee employees complete an online intake form for each employee on long-term absence (>1 month).

- A trained professional (nurse) from Mensura OHS calls the employees on long-term sickness absence and uses a telephone protocol to collect data on their sickness-absence reasons and desire to receive RTW support. Employees willing to receive support from Mensura OHS are referred to voluntary consultations with an occupational physician (OP).

- The OP evaluates the possibility of starting a reintegration program or further sickness absence.

- The employer receives individual and group reports (in accordance with confidentiality regulations and privacyprotection laws), including recommendations. Mensura OHS reviews the results and discusses possible solutions with the employer.

Results By the end of 2017, return calls will be evaluated by:

- Comparing the anticipated sick leave date with the actual return to work date

- Mapping the long-term evolution of absenteeism in companies

By the ICOH 2018 Congress, preliminary results will be available.

Discussion Return calls can establish a proactive, constructive approach to increase the chances of successful reintegration of employees on sick absence. The results may inform targeted strategic-policy advice to reduce and prevent long-term absenteeism in companies.

\section{SICK ABSENCE IN THE SÃO PAULO REGION}

D Rozemberg. Ministry of Social Security, Paraty, Brazil

\subsection{6/oemed-2018-ICOHabstracts.483}

Introduction The literature reports that many of the causal factors related to sickness absenteeism are linked to working conditions and the absence from work often means by which the worker would escape a confliting situation.Having this central question indexes is studied in Absenteeism of institutions in which the author practiced occupational medicine.

Methods Retrospective study of 6183 workers with absence periods of up to 15 days, during the years 1989 to 2004 of a private general hospital, two public health services, a public education unit and a large private food industry in the region of Ribeirão Preto. Traditional absenteeism indices (severity, frequency, average length of leave, frequency per individual and average license per person) are used according to age, length of service, occupational group, gender, former employees and employees of the same institution And employees with concomitant links at two institutions.

Result The rates are higher at the extremes of age, in women, the unskilledfoccupational group among the dismissed employees and public entities.

Discussion The profile is similar to other studies indicating motivational influence mainly on comparing concomitant double bond of workers (higher absenteeism in the public service where there is stability guaranteed by law). The double work/ home journey and greater concern about the state of health may be influencing the female sex. The occupational group presents an increase of the indices directly proportional to the decrease of the schooling and the responsibilities of the tasks. Real morbidity seems to influence the indexes of the oldest and youngest, and institutions have increased indexes since the second year of attachment (adaptation to the climate of absenteeism of each institution). The results demand a global managerial action discarding the isolated participation of the Service of Medicine of the work, usual practice in our country, in the control of the absenteeism by diseas.

\section{ESTABLISHMENT AND APPLICATION OF OCCUPATIONAL HEALTH EXPENDITURE INPUT-OUTPUT MODEL IN IRON AND STEEL ENTERPRISE}

${ }^{1} \mathrm{~F}$ Shen, ${ }^{1} \mathrm{Q}$ Zhang, ${ }^{1} \mathrm{~J}$ Meng, ${ }^{2} \mathrm{~S}$ Xiao, ${ }^{1} \mathrm{~J}$ Yuan, ${ }^{1} \mathrm{H}$ Wang, ${ }^{1} \mathrm{Y}$ Tang. ${ }^{1}$ Hebei Province Key Laboratory of Occupational Health and Safety for Coal Industry, School of Public Health, North China University of Science and Technology, Tangshan, Hebei, P.R. China; ${ }^{T}$ Tangshan Centre of Disease Control and Prevention, Tangshan, Hebei, P.R. China

\subsection{6/oemed-2018-ICOHabstracts.484}

Introduction Insufficient and unreasonable occupational health investment is one of the important reasons for the high rate of occupational diseases and accidents in iron and steel sector. The purpose of this study is to establish occupational health and safety investment prediction model of iron and steel manufacture for higher returns.

Methods The DEA model and input-output table were established. The detailed data of the input and output of each branch in a steel enterprise in 2015 were collected and the input and output efficiency of occupational health in each branch were evaluated through DEA method. The data were put into the DEA model and a list of relevant parameters calculation and adjustment scheme were obtained, and occupational health input and output data after adjustment and other relevant data were substituted into it to build prediction model.

Results According to the characteristics of the iron and steel enterprise's occupational health, occupational health funds input-output table have been established, which can reflect the input and output relationship among various departments (workshops) directly and clearly. In the branches of the iron and steel enterprise, the occupational health input output efficiency score of stainless steel plant and smoother was the highest, equal to 1 , while the cold rolling plant had the lowest, equal to 0.759 . In the cold rolling plant, only acid rolling workshop parameters met the standard of $\alpha=1, s^{-}=0, s^{+}=0$. 